\title{
Multicentre validation study of nucleic acids extraction from FFPE tissues
}

\author{
Serena Bonin - Falk Hlubek • Jean Benhattar • Carsten Denkert • Manfred Dietel • \\ Pedro L. Fernandez • Gerald Höfler • Hannelore Kothmaier • Bozo Kruslin • \\ Chiara Maria Mazzanti • Aurel Perren • Helmuth Popper • Aldo Scarpa • \\ Paula Soares • Giorgio Stanta • Patricia J. T. A. Groenen
}

Received: 8 September 2009/Revised: 12 February 2010 /Accepted: 31 March 2010/Published online: 28 July 2010

(C) The Author(s) 2010. This article is published with open access at Springerlink.com

\begin{abstract}
In most pathology laboratories worldwide, formalin-fixed paraffin embedded (FFPE) samples are the only tissue specimens available for routine diagnostics. Although commercial kits for diagnostic molecular pathology testing are becoming available, most of the current
\end{abstract}

Serena Bonin, Falk Hlubek and Patricia J. T. A. Groenen contributed equally to the realization of this paper.

Electronic supplementary material The online version of this article (doi:10.1007/s00428-010-0917-5) contains supplementary material, which is available to authorized users.

S. Bonin · G. Stanta $(\bowtie)$

ACADEM Department-University of Trieste and ICGEB, University of Trieste, Cattinara Hospital- Pathology Bldg,

Strada di Fiume 447, 34149 Trieste, Italy

e-mail: stanta@icgeb.org

F. Hlubek

Institute of Pathology,

Ludwig-Maximilians-University of München,

Thalkirchner Straße 36, 80337 München, Germany

\section{J. Benhattar}

Institute of Pathology-CHUV and University of Lausanne,

Bugnon 25, 1011 Lausanne, Switzerland

C. Denkert $\cdot$ M. Dietel

Institute of Pathology, Charité-University Medicine,

Charitéplatz 1, 10117 Berlin, Germany

\section{P. L. Fernandez}

Department of Pathology, Hospital Clínic-IDIBAPS,

University of Barcelona,

Barcelona, Spain

\section{G. Höfler}

Institute of Pathology, Labor für molekularpathologische

Diagnostik, University of Graz Medical School,

Auenbruggerplatz 25, 8036 Graz, Austria diagnostic tests are laboratory-based assays. Thus, there is a need for standardized procedures in molecular pathology, starting from the extraction of nucleic acids. To evaluate the current methods for extracting nucleic acids from FFPE tissues, 13 European laboratories, participating to the

H. Kothmaier $\cdot$ H. Popper

Institute of Pathology, Molekulare Lungen-und Pleurapathologie,

University of Graz,

Auenbruggerplatz 25, 8036 Graz, Austria

B. Kruslin

University of Zagreb-School of Medicine,

Ljudevit Jurak Department of Pathology,

Sestre milosrdnice University Hospital,

Vinogradska 29, 10000 Zagreb, Croatia

C. M. Mazzanti

Division of Surgical, Molecular and Ultrastructural Pathology,

University of Pisa and Pisa University Hospital,

Pisa, Italy

A. Perren

Institute of Pathology, Technische Universität München,

München, Germany

\author{
A. Scarpa \\ Department of Pathology and ARC-Net Research Center, \\ University of Verona, \\ Policlinico GB Rossi, Verona, Italy
}


European FP6 program IMPACTS (www.impactsnetwork. $\mathrm{eu}$ ), isolated nucleic acids from four diagnostic FFPE tissues using their routine methods, followed by quality assessment. The DNA-extraction protocols ranged from homemade protocols to commercial kits. Except for one homemade protocol, the majority gave comparable results in terms of the quality of the extracted DNA measured by the ability to amplify differently sized control gene fragments by PCR. For array-applications or tests that require an accurately determined DNA-input, we recommend using silica based adsorption columns for DNA recovery. For RNA extractions, the best results were obtained using chromatography column based commercial kits, which resulted in the highest quantity and best assayable RNA. Quality testing using RT-PCR gave successful amplification of $200 \mathrm{bp}-250 \mathrm{bp}$ PCR products from most tested tissues. Modifications of the proteinase- $\mathrm{K}$ digestion time led to better results, even when commercial kits were applied. The results of the study emphasize the need for quality control of the nucleic acid extracts with standardised methods to prevent false negative results and to allow data comparison among different diagnostic laboratories.

Keywords FFPE - Multicentre study · Molecular analyses standardisation $\cdot \mathrm{PCR} \cdot \mathrm{DNA} \cdot \mathrm{RNA} \cdot$ Isolation

\section{Introduction}

One of the major challenges in oncology is a correct prediction of individual recurrence risk and the prediction of efficacy and safety of therapy. Histopathology is only partly able to mirror and predict the clinical behaviour of individual tumours. Through the application of molecular tools, otherwise indistinguishable tumour subgroups have been identified and the definition of a precise gene mutation pattern has highlighted classes of tumours with clinical prognostic implications [1]. Moreover the application of molecular tests such as real time PCR based assays has become feasible thanks to the use of formalin-fixed paraffin embedded samples [2], which represent the most valuable source of diagnostic materials. As a consequence, in the near future molecular approaches in formalin fixed and

\section{P. Soares}

Institute of Pathology and Molecular Immunology, (IPATIMUP), University of Porto,

4200-465 Porto, Portugal

\section{P. J. T. A. Groenen}

Department of Pathology,

Radboud University Nijmegen Medical Centre,

Nijmegen, The Netherlands paraffin embedded (FFPE) material will become part of the routine process of cancer diagnostics. At the present time most of the methods applied in molecular pathology are laboratory-based assays and commercial kits not directly intended for diagnostic purposes. Therefore there is a need to establish guidelines with standardised procedures for molecular methods, starting from an analysis of the currently used methods of nucleic acids extraction.

This collaborative study includes 13 European laboratories of the IMPACTS group (www.impactsnetwork.eu) and was conducted to evaluate the performance of nucleic acids extractions using the same formalin-fixed paraffinembedded specimens. The aim of the study is to assess if the different methodologies used for nucleic acids extraction in different laboratories might affect the results.

\section{Materials and methods}

Four cases of formalin-fixed paraffin-embedded tissues were distributed to the participants in the study in two rounds. In detail, the Trieste group delivered one colorectal cancer specimen during the first control round. The Berlin group delivered an ovary cancer sample and the Graz group delivered two lung cancer cases in the second control round. Surgical specimens with a large amount of tissue were used to ensure to have sufficient material for the multicentre analysis. Comparable tissue areas distributed in 2 to 4 sections of $5 \mu \mathrm{m}$ in thickness were used per test and distinct tissue blocks of the same cases were selected for RNA and DNA extractions. The sections were collected sequentially: each following section was given to a different participant in order to obtain the most homogeneous representative tissues in all the different laboratory tests. Tissue slides were sent under vacuum at room temperature. The colon cancer samples were dated 2002, while the lung and ovarian cancer specimens were dated 2008. Each laboratory used the protocol that was routinely used for standard DNA and/or RNA extractions as reported in Supplemental 1, 2 and 3. Although interesting, it was technically not feasible to test the different extraction methods by the diagnostic laboratories. The homemade protocols for the extractions are referred to detailed references, while the commercial kits are referred to the manufacturer's manuals. Each nucleic acid extract was quantified by means of Nanodrop (ThermoScientific). The total amount of nucleic acids and $\mathrm{A}_{260} / \mathrm{A}_{280}$ results were recorded for each extract. The quality assessment for DNA extracts was performed by the use of the BIOMED-2 control gene PCR method as previously described [3]. This method is based on a multiplex PCR resulting in a ladder of fragments $(100,200,300$, and $400 \mathrm{bp})$ to check the quality and amplifiability of DNA from FFPE materials. 
In detail, the undiluted DNA sample and $100 \mathrm{ng}$ of the sample were amplified. In case no amplified band was detected (like the colon and lung specimens from participant 1), multiple DNA concentrations (10, 50, $200 \mathrm{ng})$ were amplified as well. The BIOMED-2 control gene PCR was run for all samples in one laboratory (Molecular Pathology, RUNMC, Nijmegen) and analyzed by electrophoresis on agarose gel.

For the first control round, RNA (colon cancer specimen) quality assessment by RT-PCR was performed in each laboratory using their routinely method with their usual fragment length amplification. All the protocols were based on DNA digestion and cDNA synthesis by the use of the random priming approach. In the second control round, for RNA extracts, DNase treatments and cDNA synthesis were all performed in one lab (Trieste), as previously reported [4], after re-quantification of RNA. Complementary DNAs were then submitted in dry ice to Munich (LMU) for PCR analysis as described hereafter. Quality test for RNA was performed by amplifying different fragments of PBGD (Porphobilinogen deaminase) (150 and 250 bases), B2M (Beta-2-microglobulin) (200 bases) and $\beta$-actin (103 bases) housekeeping genes. As negative control, pure DNAse treated RNAs of a representative number of samples were used in the PCR reactions for specificity testing. Because the ovarian cancer samples yielded by far the lowest amount of RNA and neither PBGD nor B2M was detectable by PCR subsequent to standard reverse transcription procedure using random primer, these RNA samples were reverse transcribed using a PCR-target specific primer ( $\beta$-actin forward, see below). The $\beta$-actin specific cDNA was amplified by PCR resulting in an amplification product of 103 bases. PCR products were analysed by agarose gel electrophoresis $(3 \% \mathrm{w} / \mathrm{v})$. For all PCR reactions, $200 \mathrm{ng}$ cDNA (50 ng control cDNA, cell line) and the AmpliTaq Gold DNA polymerase (Applied Biosystems, Darmstadt, Germany) were used with 40 amplification cycles $\left(10 \mathrm{~min} .94^{\circ} \mathrm{C} ; 40\right.$ cycles of $30 \mathrm{sec} .94^{\circ} \mathrm{C}, 30 \mathrm{sec} .60^{\circ} \mathrm{C}, 1 \mathrm{~min} .72^{\circ} \mathrm{C}$ and one cycle $10 \mathrm{~min} .72^{\circ} \mathrm{C}$ ). For the $\beta$-actin and PBGD (250 bp amplicon) specific PCR, $1.5 \mathrm{mM} \mathrm{MgCl}_{2}$ and $0.2 \mathrm{mM}$ dNTP-mix were used. The 150 bp amplicon PBGD-PCR employed $2.0 \mathrm{mM} \mathrm{MgCl} 2$ and the B2M specific PCR (200 bp) $2.5 \mathrm{mM} \mathrm{MgCl} 2$. The primer sequences were as follows:

PBGD (250 bp): forward: 5'-CTGGTAACGGCAAT GCGGCT-3', reverse: 5'-TTCTTCTCCAGGG CATGTTC-3'; PBGD (150 bp): forward: 5'-TGCCAGAGAAGAGTGT GGTG-3', reverse: 5'-AT GATGGCACTGAACTCCTG-3'; B2M (200 bp): forward: 5'-GTTGACTTACTGAAGAATGG AG-3', reverse: 5'-GATGCTGCTTACATGTCTCG-3'; $\beta$-actin (103 bp): forward: 5'-TTGCGGAT GTCCACGTCA-3', reverse: 5'-GCCCTGAGGCACTCTTCCA-3'

\section{Results}

DNA

Thirteen European participants were involved in the validation testing of DNA. The laboratories originating in Austria, Croatia, Germany, Italy, Portugal, Spain, Switzerland and The Netherlands were kept anonymous and were ranked according to the protocol type. The methods used by each participant were divided into 3 major groups, since the protocols within each group were similar.

1. DNA extraction with precipitation of the DNA either by $\mathrm{NaAc} / \mathrm{EtOH}$ (Participants $1,2,5$ ) or by isopropanol (Participants 3, 4). Participant 4 took part only in the second round of DNA validation (lung and ovary cancer specimens).

2. DNA extraction without further precipitation or purification (Participants: 6,7 and 8, the latter only for the colon cancer sample)

3. DNA extraction using silica based adsorption columns for purifying DNA (Participants: 9, 10, 11, 12 and 13).

Details on the used protocols are provided in Supplemental Tables 1 and 2. The criteria used for evaluation of the DNA extracts were: 1) the DNA yield obtained by the extraction and 2) the DNA quality assessed by the purity measured by spectral-photometry $\left(\mathrm{A}_{260} / \mathrm{A}_{280}\right)$ and by BIOMED-2 gene control PCR to test PCR-amplifiability. The median amounts of extracted DNA for each sample are reported in detail in Table 1 and Fig. 1, and show that the total amount of DNA extracted was highly dependent on the method used. The highest DNA-yields were obtained by the use of homemade methods that do not employ further purification of the DNA (Table 1, protocol type 2). Note that in these DNA extracts, the measured concentration does not reflect the actual DNA quantity because of the copresence of RNA and proteins debris, as it is apparent from the $A_{260} / A_{280}$ ratio (Supplemental Table 1). Thus, the DNA yield and concentration of these specimens are only indicative. A lower DNA yield was obtained when using column based methods or homemade methods including a DNA precipitation step. This trend was shown for all the analyzed specimens.

Differences in the purity of the DNA extracts hardly affect the PCR-amplifiability (Table 2 and Fig. 2). The quality of the DNA extracted from the lung specimens allowed amplification of the $300 \mathrm{bp}$ band of the control gene PCR for all protocols. Some protocols allowed amplification of the $400 \mathrm{bp}$ fragment, although this band was only faintly detected. For the colon sample, many protocols allowed DNA-amplification of the $200 \mathrm{bp}$ band as the maximal amplifiable length, while two homemade protocols only successfully amplified the smallest sized 
Table 1 Results on the nucleic acids extraction quantities

\begin{tabular}{|c|c|c|c|c|c|c|}
\hline \multirow[b]{2}{*}{ Sample } & \multicolumn{3}{|c|}{ DNA yield by protocol type } & \multicolumn{3}{|c|}{ RNA yield by protocol type } \\
\hline & Protocols type 1 & Protocols type 2 & Protocols type 3 & Protocols type 4 & Protocol type 5 & Protocols type 6 \\
\hline Colon ca. & $72.8 \mu \mathrm{g}(70-80)$ & $237 \mu \mathrm{g}(145-274)$ & $46.5 \mu \mathrm{g}(39-76)$ & $19.5 \mu \mathrm{g}(17-22)$ & $38.4 \mu g(30-47)$ & $48.4 \mu \mathrm{g}(12-70)$ \\
\hline Ovarian ca. & $17.4 \mu \mathrm{g}(11-26)$ & $85.8 \mu \mathrm{g}(70-101)$ & $8.1 \mu g(4-9)$ & $1.8 \mu \mathrm{g}(1.5-4.9)$ & $2.6 \mu \mathrm{g}(1.6-3.6)$ & $5.7 \mu \mathrm{g}(2.5-6.8)$ \\
\hline Lung ca 1 & $35.1 \mu \mathrm{g}(27-51)$ & $144 \mu \mathrm{g}(125-163)$ & $15.6 \mu \mathrm{g}(16-19)$ & $9.2 \mu \mathrm{g}(5-22)$ & $41.0 \mu \mathrm{g}(37-45)$ & $32.3 \mu \mathrm{g}(8-41)$ \\
\hline Lung ca. 2 & $25.9 \mu \mathrm{g}(16-37)$ & $160 \mu \mathrm{g}(134-186)$ & $16.9 \mu \mathrm{g}(15-19)$ & $8.9 \mu \mathrm{g}(6-9)$ & $20.8 \mu \mathrm{g}(19-23)$ & $22.9 \mu \mathrm{g}(7-40)$ \\
\hline
\end{tabular}

For each sample the median amount of extracted nucleic acid and the 25th and 75th centiles (in brackets) with respect of the protocol type are reported.

control amplicon of $100 \mathrm{bp}$. From one participant using a homemade protocol, DNA extracts from colon and lung specimens did not allow amplification of the control genes. Regarding the DNA extraction procedures characterised by purification steps, it seems there is no clear correlation among quantities of detected DNA and PCR performance; even for low amounts of extracted DNA the PCR performance was good.

\section{RNA}

The validation of RNA isolation methods was performed by 10 participants from 8 European countries (Austria, Germany, Croatia, Italy, Portugal, Spain, Switzerland and The Netherlands). The participants were kept anonymous using the numbering of the DNA validation tests. The extraction protocols can be divided into 3 major groups as follows (numbered sequentially according to DNA protocols):

4. RNA extraction using phenol extraction and isopropanol precipitation- homemade protocols (Participants 2, 4, 5)

5. RNA extraction using phenol extraction and isopropanol precipitation- commercial mono-phase solutions (Participants 8, 11)

6. RNA extraction using silica based columns for purification (Participants: 3, 4 only for Colon Cancer sample, 6, 7, $9,12)$

The criteria for assessing the quality of the RNA isolation method were: 1) the RNA yield and 2) the RNA quality determined by purity detection using spectral-photometry $\left(\mathrm{A}_{260} / \mathrm{A}_{280}\right)$ and by amplification methods. The RNA was isolated from a single case of colorectal cancer, two lung cancer cases and one ovary
Fig. 1 Bar graph representing the total amount of extracted DNA from colon cancer, ovarian cancer and lung cancer (2) specimens by the use of different protocol types. Light grey bars are referred to protocol type 1 (DNA extraction with precipitation step); medium grey bars are referred to protocol type 2 (DNA extraction without purifications steps) and dark grey bars are referred to protocol type 3 (DNA extraction with commercial kits based on the use of silica based columns)
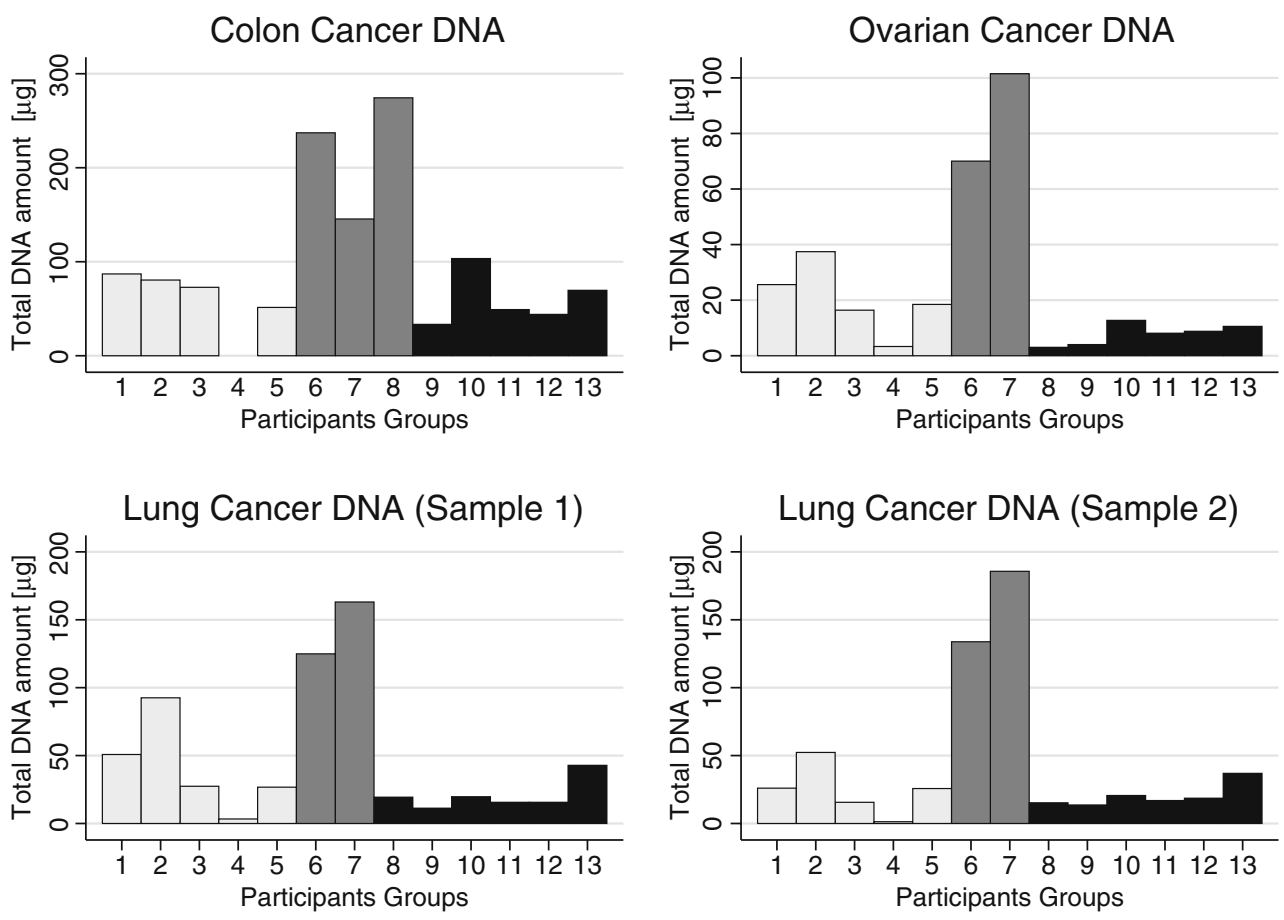
Table 2 Performance of the extracted DNAs in the BIOMED-2 gene control PCR

The performance is expressed in base pairs referred to the longest PCR fragment that was amplified. The 400 bp band, when detected, was only weakly present.

$\mathrm{nd}=$ not determined, these participants $(4,12$ and 13) did not send their DNA samples for general quality control testing.

a This participant used protocol type 2 for the colon cancer sample, as underlined.

\begin{tabular}{llllll}
\hline Protocol Type & Participant & Colon Ca. & Ovarian Ca. & Lung Ca. 1 & Lung Ca. 2 \\
\hline 1 & 1 & 0 & 200 & 0 & 0 \\
1 & 2 & 200 & 100 & 400 & 300 \\
1 & 3 & 100 & 100 & 300 & 300 \\
1 & 4 & nd & 100 & 300 & 300 \\
1 & 5 & 200 & 100 & 400 & 400 \\
2 & 6 & 200 & 100 & 400 & 300 \\
2 & 7 & 200 & 100 & 400 & 400 \\
3 & $8^{\mathrm{a}}$ & 100 & 100 & 400 & 300 \\
3 & 9 & 200 & 100 & 400 & 300 \\
3 & 10 & 200 & 100 & 300 & 400 \\
3 & 11 & 200 & 100 & 300 & 300 \\
3 & 12 & nd & 100 & 300 & 300 \\
3 & 13 & nd & 100 & 400 & 300 \\
\hline
\end{tabular}

cancer tissue. The median amount of extracted RNA is reported in Table 1 and Fig. 3. Regarding the protocol type, the RNA yield was higher with the use of commercial kits based on silica column purification (protocol type 6), followed by the use of commercial solutions and the homemade protocols. The Qiagen RNeasy FFPE kit using an extended proteinase- $\mathrm{K}$ digestion time revealed the best performance regarding the yield (Supplemental Table 4). However, when the Qiagen RNeasy FFPE kit was used by different participants, remarkable differences in RNA yield were observed (Supplemental Tables 3 and 4, Fig. 3 participant 12 vs. 7).

The RNA quality was measured by RNA purity detection using spectral-photometry $\left(\mathrm{A}_{260} / \mathrm{A}_{280}\right)$. The highest purity was obtained by silica based column purification procedures (protocol type 6) (Qiagen RNeasy FFPE kit and Roche High Pure RNA Paraffin kit) with the exception of the Gentra kit and was followed by the homemade protocol (protocol type 4) based on phenol extraction and isopropanol precipitation. The commercial solution method (protocol type 5) gained the least pure RNA measured by the $\mathrm{A}_{260} / \mathrm{A}_{280}$ absorption ratio. To further validate the RNA quality a standardized PCR procedure was used with four different amplicon lengths (103 bp, 150 bp, 200 bp, 250 bp) after standard reverse transcription. The original RNA of the samples was used as negative control resulting in no PCR product. Taken together, the column based commercial kits (protocol type 6 - Qiagen RNeasy FFPE kit and Roche High Pure RNA Paraffin kit) yielded the best assayable RNA quality (Table 3, Fig. 4). Interestingly the performance of the RNA in the RT-PCR reaction did not always correlate with RNA purity data, as RNA obtained by commercial solutions with the least pure RNA (protocol type 5) performed better than RNA extracted by homemade protocols (protocol type 4; see Table 3).

\section{Discussion}

Diagnostic methodologies need per definition a basic level of standardization in order to obtain concordance in the responses among hospitals. Immunohistochemistry (IHC) is the most widely used method to detect proteins in FFPE tissues for diagnostic purposes. Despite the standardization of immunohistochemical staining protocols, some factors could still vary among samples and laboratories, such as tissue fixation (duration), choice of antibodies, and the threshold for interpretation of positive immunostaining, which may dramatically

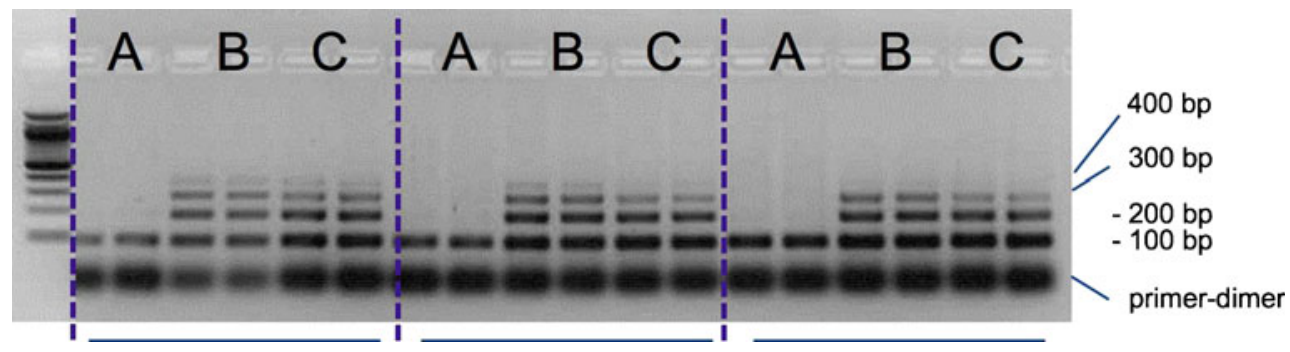

Fig. 2 BIOMED-2 control gene PCR results of the extracted DNAs in duplicate of group 9, 6 and 2 (protocol type 3,2 and 1 respectively). DNA was extracted from ovary (a), lung 1 (b) and lung 2 (c). The size of the amplified products is indicated. The lowest thick band represents primer-dimer products 
Fig. 3 Bar graph representing the total amount of extracted RNA from colon cancer, ovarian cancer and lung cancer (2) specimens by the use of different protocol types. Light grey bars are referred to protocol type 4 (RNA extraction with homemade protocols); medium grey bars are referred to protocol type 5 (RNA extraction with monophasic commercial solutions) and dark grey bars are referred to protocol type 6 (RNA extraction with commercial kits based on the use of silica based columns)
Colon Cancer RNA

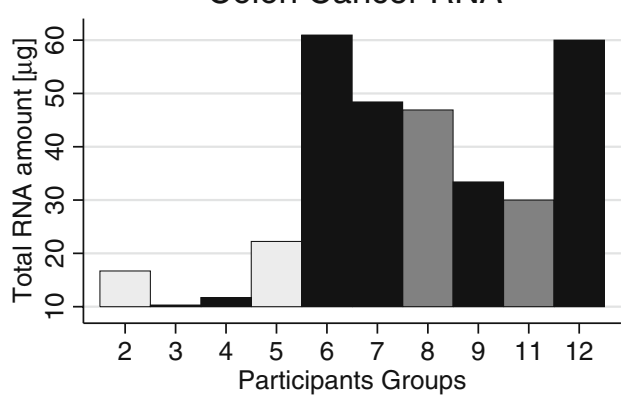

Lung Cancer RNA (Sample 1)

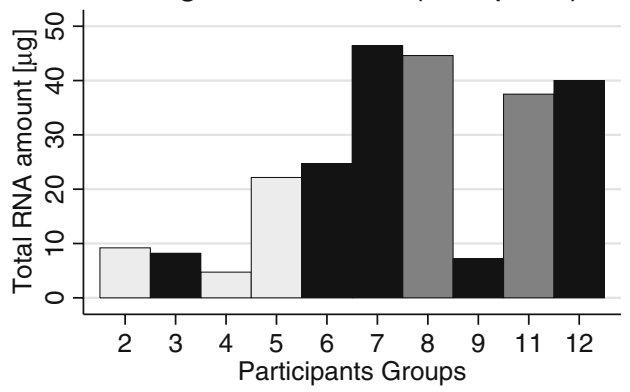

Ovarian Cancer RNA

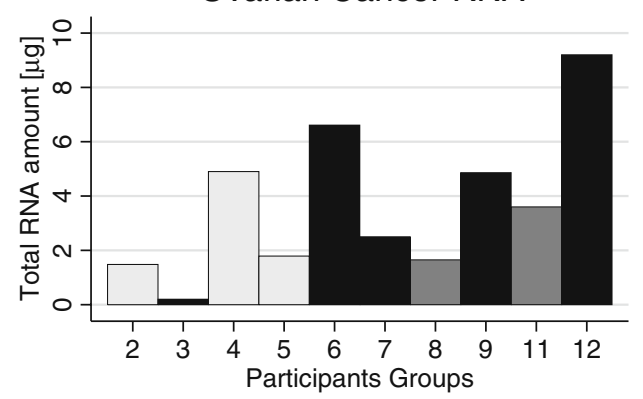

Lung Cancer RNA (Sample 2)

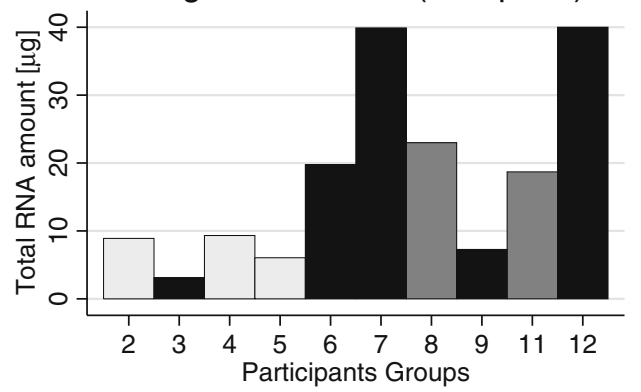

affect test accuracy and reproducibility. In any case IHC is considered an accurate diagnostic method because there are guidelines and inter-laboratory quality controls through the cross-testing of cases that guarantee the reliability of the assays. Nowadays, there is great interest and need for molecular pathology tests in order to better characterize pathologies and better define the individual patient profile for tailored therapy. In the present study, we have systematically compared the results of different homemade and commercial protocols for DNA and RNA extraction on the same set of FFPE tissue specimens used in several laboratories in order to define reliable criteria on nucleic acid extraction from FFPE tissues.

The design of this multicentre study allows determining the specific effects of the different extraction protocols, since the quality control experiments and interpretation of the multicentric results were performed in a single laboratory. Nonetheless, we cannot entirely exclude the possible effects of additional parameters, such as different technicians and laboratory equipments, which may influence the results. However, as the extractions were performed by experienced technicians in molecular diagnostic laboratories, we anticipate a minimal effect of these parameters.

The FFPE tissues used in this study originate from routine diagnostics of three different pathology departments. Hence it may well be possible that fixation time and the size of the tissue pieces used, which is important for the fixation rate, varies. Formalin not only cross-links proteins and nucleic acids, it also modifies RNA by adding monomethylol groups to all the four bases blocking reverse transcription [5]. However it has been shown that the efficiency of extracting amplifiable RNA and DNA from FFPE tissue is inversely proportional to the fixation time [6, 7] and thus standardized fixation conditions are important. This was not specifically addressed in the current study since all laboratories used serial sections of the same tissue block of each cancer tissue.

\section{DNA}

DNA extraction protocols that used purification of the extracted DNA, either by precipitation (protocol type 1) or by using silica-based columns (protocol type 3) gave comparable results in terms of yield and purity of the DNA. The apparent yield of DNA by the use of these protocols is less comparable to protocols that do not employ any purification (protocol type 2), which is not surprising, since the measured DNA-concentration in the unpurified samples reflects the presence of RNA and DNA. Yield and concentration from protocols that do not employ purification steps is thus not accurate since degraded RNAs as well as protein debris are also quantified, overestimating thereby the real DNA amount.

The PCR-amplifiability of the DNA samples was not drastically affected by the use of different DNA-extraction protocols. Our study showed that the measurement of amplifyability of the DNA by performance of the BIOMED-2 control gene PCR is the preferred parameter, superior to spectrophotometrical determination of the $\mathrm{A}_{260} / \mathrm{A}_{280}$ ratio, to measure DNA-quality for diagnostic molecular testing. In general, DNA obtained from FFPE samples that allows amplification of $300 \mathrm{bp}$ is considered as good DNA-quality and can be 
Table 3 Results on RNA quality assessment by PCR

\begin{tabular}{llllll}
\hline $\begin{array}{l}\text { Protocol } \\
\text { Type }\end{array}$ & Participant & $\begin{array}{l}\text { Colon } \\
\mathrm{Ca}^{\mathrm{a}}\end{array}$ & $\begin{array}{l}\text { Ovarian } \\
\mathrm{Ca}\end{array}$ & $\begin{array}{l}\text { Lung } \\
\text { Ca. } 1\end{array}$ & $\begin{array}{l}\text { Lung } \\
\text { Ca. 2 }\end{array}$ \\
\hline 4 & 2 & 150 & 103 & 200 & 200 \\
4 & $4^{\mathrm{b}}$ & $\underline{200}$ & 103 & 200 & 200 \\
4 & 5 & 160 & 103 & 200 & 200 \\
5 & 8 & 127 & 103 & - & 250 \\
5 & 11 & 250 & 103 & 250 & 200 \\
6 & 3 & 160 & 103 & 150 & - \\
6 & 6 & 185 & 103 & 250 & 250 \\
6 & 7 & 200 & 103 & 250 & 250 \\
6 & 9 & 110 & 103 & - & - \\
6 & 12 & 293 & 103 & 250 & 250 \\
\hline
\end{tabular}

Results are expressed in base pairs referred to the longest amplifiable PCR product.

The larger the PCR product, the better the RNA quality was considered.

a no PCR for longer amplicon was performed in the first round of testing; the analysed housekeeping genes were: ACTB (Beta-Actin), PBGD (Porphobilinogen deaminase), PDHB (Pyruvate dehydrogenase, beta), GUSB (Glucuronidase, beta), FGFR3 (Fibroblast growth factor receptor 3).

b This participant used for colon cancer specimen the protocol type 6, as underlined.

(-) no PCR product was obtained (150 bp or larger amplicons).

used for many molecular tests, including clonality testing using the BIOMED-2 primers and protocols [8]. Array comparative genomic hybridization (aCGH) was successful using DNA samples from FFPE tissues, which allowed amplifying $200 \mathrm{bp}$ in the BIOMED-2 control gene PCR [9]. Based on evaluation of the DNA-amplifyability, there is not a single DNA-extraction protocol that is highly superior to others. The majority of the DNA-extraction protocols, except for the DNA-extraction protocol by participant 1 , give similar and comparable results. There was only a minor difference in outcome, showing less performance of the DNA-extraction protocol used by participants 3 and $8 \mathrm{a}$. However, as this was seen only in one of the four tested samples, there is no solid reason to avoid the use of these protocols.

Upon selection of the protocol to use in a diagnostic laboratory, also the requirements for the specific molecular test should be taken into consideration. It should be realised that molecular tests that require a standardized input of DNA, should use purified DNA-samples, allowing the most accurate DNA-quantification. For complex multiplexed PCRs or tests that require a specific accurate input of DNA per PCR test, like B- /T-cell clonality assessment, [8], as well as for application of array-CGH [6], MLPA-based tests [7], we strongly recommend using type 3 protocols that use silica based adsorption columns for purifying DNA.

For other molecular tests like PCR followed by direct sequencing, however, purification may not be essential. The use of protocols without further purification (protocol type 2) has an additional advantage, it is more rapid and less expensive compared to DNA-protocols that employ purification steps. We therefore recommend the use of a simple DNAprotocol, such as the type 2 protocols (DNA extractions without further purification or precipitation), for general molecular tests as mutation and translocation detection. Whichever the method used, it is highly recommended to employ only optimized and controlled reagents. This can be an important source of result variability.

\section{RNA}

The RNA isolation methods affected the yield of the extracted RNA, even when extraction conditions (proteinase $\mathrm{K}$ incubation time and temperature) were comparable (Supplemental Table 3). Proteinase $\mathrm{K}$ digestion is an important step affecting the RNA yield. In fact, we observed that an extended digestion time resulted in a more efficient extraction, especially from colon and ovarian tumour tissue using the Qiagen RNeasy FFPE kit. This is consistent with previous reports demonstrating that increas-

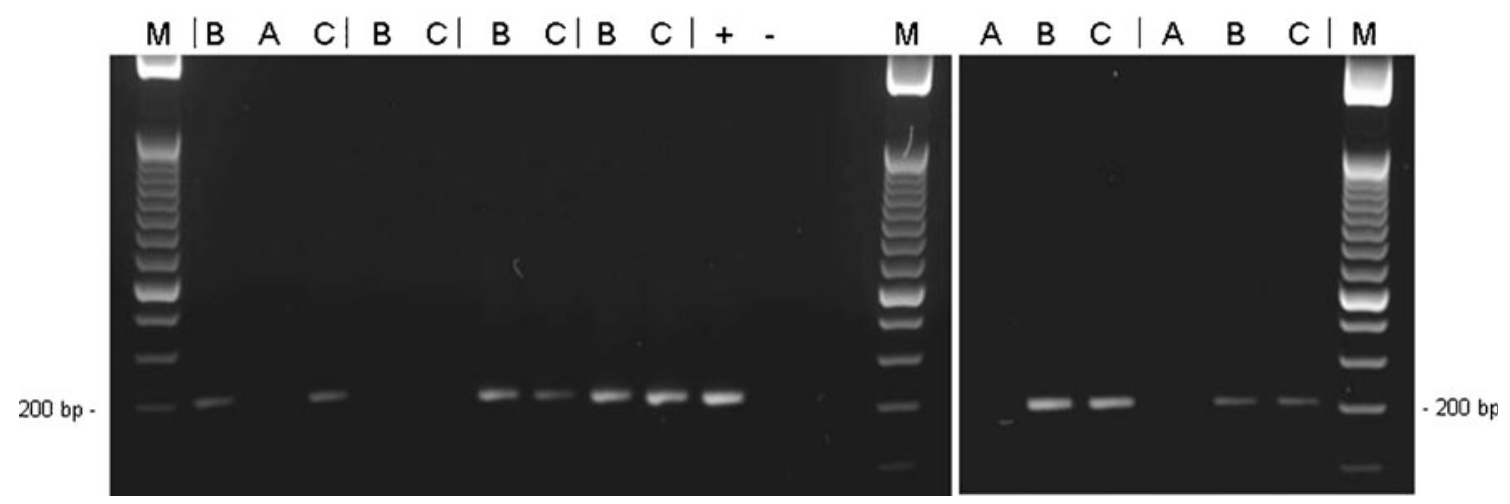

Fig. 4 B2M housekeeping gene specific RT-PCR results of the extracted RNAs of the group 2, 11, 6, 3, 7 and 12 (protocol type 4, 5 and four times 6 , respectively). RNA was extracted from ovary (a), lung 1 (b) and lung 2 (c). The PCR products were separated in $3 \%$ $(w / v)$ agarose gels. The size of the amplification products is indicated (200 bp). M: size marker (50 bp DNA Ladder, Invitrogen, Karlsruhe, Germany) 
ing proteinase $\mathrm{K}$ digestion time improved the RNA yield [6, $10,11]$. Formalin fixation preserves cellular structures by crosslinking biomolecules and thus traps nucleic acids and prevents the extraction of amplifiable RNA and DNA. By extending the digestion time to at least 16 hours, proteinase $\mathrm{K}$ is thought to release protein cross-linked nucleic acids more efficiently to permit subsequent RNA/DNA isolation, e.g. by column based methods [6]. Surprisingly, extended proteinase $\mathrm{K}$ incubation had no effect on the RNA quality evaluated by RT-PCR.

The RNA quality assessment by spectral photometry did not correlate with the maximum amplifiable length (Tables 1 and 3). The ratio $A_{260 / 280}$ is an indicator of possible contaminants [12] and the presence of inhibitors for subsequent reactions, however, this measurement is highly variable [13] and does not assess the length of the RNA extracted. Similarly, the widely used quality assessment by capillary electrophoresis (Bioanalyzer or Experion) is not predictive of the utility of RNA samples isolated from FFPE tissue in molecular analyses, since the most limiting factor for RT-PCR and presumably other enzymatic procedures, is the chemical modification of RNA by formaldehyde, which is not resolved by electrophoretic assays $[10,14]$.

Regarding the high degree of degradation of RNA in FFPE tissues, the ability of amplifying $250 \mathrm{bp} \mathrm{PCR-fragments}$ indicates RNA of very good quality. Nevertheless, the successful amplification of target mRNA fragments $\geq 200 \mathrm{bp}$ in length was considered good RNA quality [11, 15]. All isolation methods resulted in RNA of useful quality for expression analyses in archival and diagnostic tissues, since shorter amplicons are sufficient for quantitative PCR [1517]. This study reveals that column based methods (protocol type 6) provided best RNA quality assessed by RT-PCR from most of the tissues. Moreover these methods, in comparison to homemade protocols and commercial monophasic solutions, are less time-consuming by omitting the precipitation step to isolate the RNA. Small adjustments of the manufacturer's instruction (e.g. proteinase $\mathrm{K}$ digestion) may have caused inter-laboratory variability both in RNA quantity and quality, which is consistent with earlier reports demonstrating that different results were obtained by different groups using the same commercial kits $[10,15]$.

Although homemade RNA extraction methods (protocol type 4) or commercial solutions (protocol type 5) may be suitable for certain applications in research and diagnostics using short amplicons (below $160 \mathrm{bp}$ ), our results demonstrate that among the analyzed methods, particularly the Qiagen RNeasy FFPE kit including an extended proteinase-K digestion period is recommended. Due to the observed interlaboratory variability, further standardization of the techniques, including commercial kits, is recommended for research and diagnostic applications in molecular pathology.
Acknowledgements We are grateful to the teams of the IMPACTS group and their technicians for their support to make this European collaboration successful. We particularly acknowledge:

Dr. Andreas Jung, Beate Luthardt and Sabine Pfeiffer (LMU, Munich), Birgit Geist (Technische Universität, Munich), Annemiek W. M. van Raaij and Paul D.M. Rombout (RUNMC, Nijmegen), Giorgio Basili and Marisa Donada (Trieste), Marina Montresor, Maria Scardoni and Anna Bertolaso (Verona), Martina Susa (Zagreb), Dr. Dolores Colomer and Xarxa de Bancs de Tumors de Catalunya for technical assistance (Barcelona), Hugo Seca (Porto), Andrea Hofmann, Elisabeth Lackinger and Martina Wild (Graz, Labor für molekularpathologische Diagnostik), Iris Halbwedl (Graz, Research Unit for Molecular Lung- and Pleurapathology). We also thank Dr. Valentina Melita for the English revision of the manuscript.

Conflict of interests The authors declare no conflicts of interests, but F.H. received funding from Roche Diagnostics GmbH, Penzberg, Germany.

Open Access This article is distributed under the terms of the Creative Commons Attribution Noncommercial License which permits any noncommercial use, distribution, and reproduction in any medium, provided the original author(s) and source are credited.

\section{References}

1. Dietel M (2007) Predictive medicine: incipient reality or fata morgana? J Pathol 212:353-355

2. Paik S, Tang G, Shak S et al (2006) Gene expression and benefit of chemotherapy in women with node-negative, estrogen receptorpositive breast cancer. J Clin Oncol 24:3726-3734

3. van Dongen JJ, Langerak AW, Bruggemann M et al (2003) Design and standardization of PCR primers and protocols for detection of clonal immunoglobulin and T-cell receptor gene recombinations in suspect lymphoproliferations: report of the BIOMED-2 Concerted Action BMH4-CT98-3936. Leukemia 17:2257-2317

4. Nardon E, Donada M, Bonin S et al (2009) Higher random oligo concentration improves reverse transcription yield of cDNA from bioptic tissues and quantitative RT-PCR reliability. Exp Mol Pathol 87:146-151

5. Masuda N, Ohnishi T, Kawamoto S et al (1999) Analysis of chemical modification of RNA from formalin-fixed samples and optimization of molecular biology applications for such samples. Nucleic Acids Res 27:4436-4443

6. McKinney MD, Moon SJ, Kulesh DA et al (2009) Detection of viral RNA from paraffin-embedded tissues after prolonged formalin fixation. J Clin Virol 44:39-42

7. Srinivasan M, Sedmak D, Jewell S (2002) Effect of fixatives and tissue processing on the content and integrity of nucleic acids. Am J Pathol 161:1961-1971

8. Groenen PJTA, Langerak AW, van Dongen JJM et al (2008) Pitfalls in TCR gene clonality testing: teaching cases. J Hematopathol 1:97109

9. van Beers EH, Joosse SA, Ligtenberg MJ et al (2006) A multiplex PCR predictor for aCGH success of FFPE samples. Br J Cancer 94:333-337

10. Abramovitz M, Ordanic-Kodani M, Wang Y et al (2008) Optimization of RNA extraction from FFPE tissues for expression profiling in the DASL assay. Biotechniques 44:417-423

11. Chung JY, Braunschweig T, Hewitt SM (2006) Optimization of recovery of RNA from formalin-fixed, paraffin-embedded tissue. Diagn Mol Pathol 15:229-236 
12. Manchester KL (1996) Use of UV methods for measurement of protein and nucleic acid concentrations. Biotechniques 20:968970

13. Wilfinger WW, Mackey K, Chomczynski P (1997) Effect of $\mathrm{pH}$ and ionic strength on the spectrophotometric assessment of nucleic acid purity. Biotechniques 22(474-476):478481

14. von Ahlfen S, Missel A, Bendrat K et al (2007) Determinants of RNA quality from FFPE samples. PLoS ONE 2:e1261

15. Ribeiro-Silva A, Zhang H, Jeffrey SS (2007) RNA extraction from ten year old formalin-fixed paraffin-embedded breast cancer samples: a comparison of column purification and magnetic beadbased technologies. BMC Mol Biol 8:118

16. Abrahamsen HN, Steiniche T, Nexo E et al (2003) Towards quantitative mRNA analysis in paraffin-embedded tissues using real-time reverse transcriptase-polymerase chain reaction: a methodological study on lymph nodes from melanoma patients. J Mol Diagn 5:34-41

17. Li J, Smyth P, Cahill S et al (2008) Improved RNA quality and TaqMan Pre-amplification method (PreAmp) to enhance expression analysis from formalin fixed paraffin embedded (FFPE) materials. BMC Biotechnol 8:10 